\title{
Prevalence and associated factors of intestinal parasite infection by HIV infection status among asymptomatic adults in rural Gabon
}

\author{
Jeanne Vanessa Koumba Lengongo ${ }^{1}$, Bedrich Pongui Ngondza ${ }^{1}$, Bridy Moutombi Ditombi ${ }^{1}$, \\ Noé Patrick M’Bondoukwé ${ }^{1}$, Jacques Mari Ndong Ngomo ${ }^{1}$, Arnaud Mongo Delis ${ }^{2}$, \\ Princilia Bouyi Lekounga ${ }^{1}$, Marielle Bouyou-Akotet ${ }^{1}$, Denise Patricia Mawili-Mboumba ${ }^{1}$
}

1. Faculty of Medecine, Department of Parasitology Mycology.

2. Centre de Traitement Ambulatoire VIH/SIDA.

\begin{abstract}
Introduction: Intestinal parasites infections are endemic in Gabon. Nevertheless, they are rarely described in people living with HIV (PLHIV).

Objective: The frequency of intestinal parasite infection was estimated and compared between HIV-positive and HIV uninfected individuals in Gabon; factors associated with intestinal parasites were also analysed.

Material and Methods: Using a cross-sectional study design sociodemographic data, life style habits, antiretroviral therapy, cotrimoxazole use and CD4 cell count were recorded.. Stool samples from participants living in Koulamoutou and Oyem were analysed using microscopy. Chi-squared or fisher's exact tests and logistic regression were performed.

Results: Among participants ( $\mathrm{n}=332)$, female gender was predominant $(73.7 \% ; \mathrm{n}=135 / 183)$ and the median age was 45 [33-57] years old. Among 183 samples, 53.6\% ( $n=98 / 183)$ were infected by intestinal parasites. The proportion was higher $(72.1 \%)$ in HIV negative participants compared to PLHIV $(42.6 \%)$ ( $\mathrm{p}<0.01)$. PLHIV were more frequently poly-infected. Infection was frequent in patients using external toilets and tap water $(>70.0 \%)$.

Conclusion: Prevalence of intestinal parasites is higher in seronegative participants but polyparasitism is more frequent in PLHIV. Strategies are focused on HIV negative population, but this study shows the importance of sensitization for PLHIV to improve their quality of life.

Keywords: Intestinal parasites; Human immunodeficiency virus; cotrimoxazole; CD4 cell; Gabon.

DOI: https://dx.doi.org/10.4314/ahs.v20i3.5

Cite as: Lengongo JVK, Ngondzৃa BP , Ditombi BM, M'Bondonkwé NP, Ndong Ngomo JM, Delis AM, et al. Prevalence and associated factors of intestinal parasite infection by HIV infection status among asymptomatic adults in rural Gabon. Afri Health Sci. 2020;20(3): 1024 1034. https:// dx.doi.org/10.4314/abs.v20i3.5
\end{abstract}

\section{Background}

Intestinal parasite infections (IPIs) affect about half of the world's population, especially in developing countries where environmental conditions are favorable to their development. ${ }^{1}$ In sub-Sahara Africa, 36.7 million people are living with HIV (PLHIV) and are also exposed to several infectious diseases including intestinal parasitic infections that threaten the health of these people. $^{2,3}$

In absence of highly active antiretroviral therapy (HAART), the destruction of the immune system due to HIV leads to greater susceptibility to opportunistic

\section{Corresponding author: \\ Denise Patricia Mawili-Mboumba, Faculty of Medecine, Department of \\ Parasitology Mycology. \\ Email:dpmawili@gmail.com}

and other intestinal parasites. ${ }^{4}$ Other parasitic diseases such as blastocystosis of which prevalence varies between 20 to $50 \%$ in PLHIV, giardiasis and entamoebiasis are common, even in the absence of diarrhea..$^{5-7}$ HIV and parasitic infections interact with each other, potentially leading to activation of HIV replication and accelerating disease progression from HIV infection to AIDS. ${ }^{8,9}$ The risk of co-infection of these diseases (helminths infection, intestinal protozoa)were shown to be higher in PLHIV with CD4 cell counts low 200cells / $\mathrm{mm}^{3,5}$.

Moreover, co-infections may worsen the progression of AIDS. ${ }^{10-13}$ In Gabon, soil transmitted helminths (STH) and intestinal protozoa asymptomatic carriage is frequent. M'Bondoukwé et al found a high proportion of IPI carriers $(75 \%)$ in shanty towns of Libreville; Blastocystis sp was the main pathogen detected. ${ }^{14}$ In another study, protozoa and helminths were found in $61.2 \%$ of population in rural and urban areas. ${ }^{15}$ These studies 
were performed in patients whose HIV status was not determined. Blastocystis sp is an emergent protozoan; a significant association was observed between immunosuppression among PLHIV and its occurrence. ${ }^{16}$

The Parasitic Diseases National Control Program performs surveys to monitor parasitic diseases throughout Gabon. Data on IPIs in PLHIV are scarce although this population is also exposed to opportunistic and non-opportunistic parasitic diseases. ${ }^{4,17}$ PLHIV, are approximately 53000 people, and represent between 2 to $13 \%$ of the Gabonese population and are followed up in care and treatment centre (CTC) for PLHIV in the whole country. ${ }^{18}$ They are not targeted by IPIs preventive strategies although their living conditions did not differ, from the ones of the rest of the population. IPIs control strategies objectives may not be achieved without investigating the burden of IPIs in the whole population including PLHIV.

The present study aimed to compare the prevalence of intestinal parasites in people according to their HIV infection status and CD4 cell counts in two rural areas, Oem and Koulamoutou where no data on intestinal parasites had been recorded.

\section{Materiel and methods \\ Study area}

The study was carried out in June 2016 in two regions of Gabon where data on IPIs are scarce: Koulamoutou, South Eastern part of Gabon with a population estimated at 16222 inhabitants and Oyem in the north with a population of near 60,000 inhabitants. The climate is equatorial with two rainy and two dry seasons, temperatures ranges of $23-33^{\circ} \mathrm{C}$ and $80 \%$ humidity on average. In the rural areas of Gabon, water is mainly obtained from public water pumps or rivers. The dwellings are made of terracotta and the streets are not always tarred. The main activity in these areas is agriculture.

\section{Study population \\ Study design}

This was a prospective comparative cross-sectional study. Asymptomatic PLHIV attending their routine follow-up visits in two HIV care and treatment centers (CTCs) were invited to participate in the study. For the comparison of intestinal parasites prevalence, data from volunteer adults, accompanying patients, were also collected in the Regional Hospital of Koulamoutou which is located near CTC.

\section{Data collection}

Participants were included after being given informa- tion about the study. Briefly, data on demography (age, sex and education level), self-medication with anthelminthic drugs, type of drinking and housekeeping water, presence of toilets in/or outside the house were recorded for both groups using a structured questionnaire. Among PLHIV, antiretroviral treatment (ART) use and cotrimoxazole (CTX) prophylaxis, CD4 cells counts were recorded from patients HIV clinic registers.

\section{Inclusion criteria for seronegative participants and PLHIV:}

Only individuals, including the ones accompanying the PLHIV, who accepted to be tested for HIV, who had been living at the site for at least six (6) months before the start of the study and who gave their written informed consent were recruited.

\section{Exclusion criteria for seronegative participants and PLHIV:}

Participants who had diarrhoea or abdominal pain and anti-parasitic intake in the 2 weeks prior to collection were excluded.

\section{HIV infection diagnosis}

HIV test was performed for all volunteers not followed up at the HIV CTC according to the Gabonese national HIV testing algorithm. None were found positive.

\section{Study procedures: specimen collection and pro- cessing}

Clean well-labelled stool collection vials were provided to the participants with clear instructions to ensure that stool samples would be correctly collected. Each vial was identified by a code number specific to each participant. They were instructed to use the spatula provided to transfer a thumb-sized faecal sample to the container making sure that the sample was not contaminated with urine. Stool specimens were processed and examined microscopically for parasite detection.

\section{Direct microscopic examination}

A small amount of stool was mixed with a drop of saline and was examined under a light microscope for the observation of motile parasites. STH including Schistosoma (S.) intercalatum eggs, cysts and vegetative forms of Entamoeba sp, Blastocystis sp, G. duodenalis can be detected with this method.

\section{MIF (Merthiolate)-Iodine-Formaldehyde) concen- tration}

The MIF concentration (MIFc) method was carried out 
as described by Sapero and Lawless. ${ }^{15,19}$ MIFc is a simple and rapid staining method in which faecal specimen is concentrated by crushing in thiomersal-formaldehyde solution and stained with 5\% Lugol's solution. Eggs of A. lumbricoides, T. trichiura, S. intercalatum, cysts and vegetative forms of amoeba and $G$. duodenalis, cysts of Blastocystis spare stained. The use of a combination of MIF and Lugol's solution for staining is sensitive for the detection, fixation and storage of vegetative forms and cysts of protozoa. Parasite species observed after direct examination are detected equally after MIFc. Samples were considered positive upon the detection of a single parasite in the sample.

\section{Parasite culture}

Parasites culture was performed as previously described for N. Americanus and S. Stercoralis larvae detection. ${ }^{15,20 \text {, }}$ ${ }^{21}$ The parasite culture was considered as positive if at least one larva was present.

\section{Modified Ziehl Neelsen staining method}

Modified Ziehl Neelsen method was used for the identification of Cryptosporidium sp and Isospora belli $i^{22}$. Slides were examined under a microscope at a magnification of $\times 100$. Samples were considered as positive upon the detection of at least one parasite in the sample.

The samples that tested negative using direct microscopic examination were confirmed after staining and the results were returned to the participants.

\section{ART use}

According to the national guidelines, the drugs administered as first line antiretroviral therapy (ART) were $\mathrm{Zi}$ dovudine (AZT) or Tenofovir (TDF) plus Lamivudine (3TC) plus Efavirenz (EFV) or Nevirapine (NVP); for the second line treatment it was Abacavir $(\mathrm{ABC})$ or $\mathrm{Zi}$ dovudine (AZT) plus Didanosine (DDL) plus Lopinavir/r (Lopi/rito).

\section{Definitions of variables of interest}

- Patients who had a positive MIF concentration or stool culture or modified Ziehl Neelsen staining are classified as having intestinal parasites.

- $\quad$ Presence of at least two different intestinal parasite species was considered as "multiple parasite infections" or "polyparasitism".

- Person was considered to be educated if they completed/attended primary school.

- type of drinking and housekeeping water indicates the source of the water (tap, well, river and mix) presence of toilets in/or outside the house indicates the location of the toilets

\section{Data analysis}

StatView 5.0 (SAS Institute Inc) was used for data analysis. Age and CD4 count were presented in medians with interquartile (IQR) ranges (non-Gaussian distribution). Differences of the frequency between groups (PLHIV and seronegative patient) and associated factors were assessed using chi-squared or Fisher's exact tests. $P$ values below 0.05 was considered significant, if $\mathrm{p}$ values were between 0.05 and 0.10 , it was considered as a trend. Crude odds ratios (cORs) and 95\% confidence intervals (CIs) were used to assess the association between intestinal parasite groups, and age, education level, type of water, use of external toilet, cotrimoxazole use and CD4 level count. For all these tests, the difference was considered significant if $\mathrm{P}<0.05$. All the reported $\mathrm{P}$-values are for two-tailed tests.

Logistic regression was performed to estimate the adjusted odds ratio $(\mathrm{aOR})$ between intestinal parasite and all variables with a $\mathrm{p}<0.2$, a multivariate mixed logistic regression model using likelihood ratio estimation for discrete choice modelling of small datasets was performed. The aORs and their 95\% CIs were calculated. Associations were found significant if $\mathrm{P}$ values were below 0.05 and a trend was indicated if $\mathrm{P}$-values were between 0.05 and 0.10 .

\section{Ethical considerations}

The study protocol was authorized by the Ministry of Public Health and approval of the National Ethics Committee was obtained in February 2016 (PROT $\mathrm{N}^{\circ} 003 / 2016 / \mathrm{SG} / \mathrm{CNE}$ ).

Informed consent was obtained. Biological testing was offered to participants, appropriate treatment according to national recommendations was administered by the specialist physician for any participant infected with pathogenic protozoa or STH.

\section{Results}

Sociodemographic characteristics of the study population

During the study period, 332 individuals accepted to participate in the study; among them 233 were PLHIV. A total of 183 (55\%) participants brought their stool for analysis; they were asymptomatic and not actively detected. The majority were female $(73.7 \% ; n=135 / 183)$ and their median age was 45 [33-57] years old. Among these participants, more than half of them used tap water as source of drinking water $(77.7 \% ; n=133 / 171)$ and for housekeeping $(66.4 \% ; n=101 / 152)$ (Table 1). 


\begin{tabular}{|c|c|c|c|c|c|c|}
\hline & \multirow[t]{2}{*}{ All } & \multicolumn{2}{|c|}{ PLHIV } & \multicolumn{2}{|c|}{ HIV negative } & \multirow{2}{*}{$\begin{array}{c}\begin{array}{c}P \\
\text { value }\end{array} \\
0.9\end{array}$} \\
\hline Gender & & $\begin{array}{c}n \\
(n=115)\end{array}$ & $\%$ & $\begin{array}{c}n \\
(n=68)\end{array}$ & $\%$ & \\
\hline Females & 135 & 85 & 73.9 & 50 & 73.5 & \\
\hline Males & 48 & 30 & 26.1 & 18 & 26.5 & \\
\hline Age (years) & 183 & $(n=115)$ & & $(n=68)$ & & $<0.01^{*}$ \\
\hline$<25$ & 29 & 6 & 5.2 & 23 & 33.8 & \\
\hline $25-55$ & 102 & 76 & 66.1 & 26 & 38.2 & \\
\hline$>55$ & 52 & 33 & 28.7 & 19 & 27.9 & \\
\hline Education & 183 & $(n=115)$ & & $(n=68)$ & & 0.8 \\
\hline No & 25 & 16 & 13.9 & 9 & 13.3 & \\
\hline yes & 158 & 99 & 86.1 & 59 & 86.7 & \\
\hline $\begin{array}{l}\text { Housekeeping } \\
\text { water type }\end{array}$ & 152 & $(n=85)$ & & $(n=67)$ & & $<0.01^{*}$ \\
\hline Tap & 101 & 50 & 58.8 & 51 & 76.1 & \\
\hline well & 2 & 2 & 2.4 & 0 & 0.0 & \\
\hline river & 25 & 14 & 16.5 & 11 & 16.4 & \\
\hline $\operatorname{mix}$ & 25 & 19 & 22.3 & 6 & 9.5 & \\
\hline Drinking water & 171 & $(n=103)$ & & $(n=68)$ & & $<0.01^{*}$ \\
\hline Tap & 133 & 80 & 77.7 & 53 & 77.9 & \\
\hline well & 29 & 14 & 13.6 & 15 & 22.1 & \\
\hline river & 9 & 9 & 8.7 & 0 & 0.0 & \\
\hline Toilet & 148 & $(n=85)$ & & $(n=63)$ & & \\
\hline & & & & & & 0.8 \\
\hline inside & 34 & 13 & 15.2 & 11 & 17.5 & \\
\hline outside & 124 & 72 & 84.7 & 52 & 82.5 & \\
\hline Use of CTX & & $(n=103)$ & & & & \\
\hline Yes & & 59 & 43.8 & - & - & \\
\hline no & & 44 & 56.2 & - & - & \\
\hline On ART & & $(n=99)$ & & & & \\
\hline No & & 3 & 3.0 & - & - & \\
\hline First line & & 92 & 92.9 & - & - & \\
\hline Second line & & 4 & 4.1 & - & - & \\
\hline $\begin{array}{l}\text { CD4 cell count } \\
\left(/ \mathrm{mm}^{3}\right)\end{array}$ & & $(n=88)$ & & & & \\
\hline$<200$ & & 18 & 20.5 & - & - & \\
\hline $200-500$ & & 41 & 46.6 & - & - & \\
\hline$>500$ & & 29 & 32.9 & - & - & \\
\hline
\end{tabular}

Likewise, more than two-third of uninfected participants $(n=68 / 99)$ brought back their stools for analysis, while only $49 \%(n=115 / 233)$ of the PLHIV brought their stools. According to the median age, PLHIV were older $(\mathrm{p}<0.01)$ : 47 [39-57] years old and two third of them $(66.1 \% ; \mathrm{n}=76)$ were aged between 25 and 55 years old. The median age of HIV negative individuals was 31 [20-55] years old. In this group, volunteers were almost equally distributed in the different age groups (table1). Among PLHIV, ART and CTX intake was not reported for $13.9 \%(n=16)$ and $10.4 \%(n=12)$ of participants, respectively. Among those with complete data, 43\% ( $n=59 / 103)$ used CTX and more than $97 \%$ ( $\mathrm{n}=96 / 99)$ were on ART; mainly the first line therapy $(92.9 \% ; \mathrm{n}=92)$ and $67.1 \%(\mathrm{n}=59)$ had low CD4 cell count (table 1).

\section{Prevalence of intestinal parasites in the study pop-} ulation

In the study population, $53.6 \%(\mathrm{n}=98 / 183)$ of the patients were infected by intestinal parasite; among them 80 participants had a mono infection and 18 were infected by more than one parasite species (Table 2) mainly by two species of parasites $(n=13)$. IPIs were predominantly due to protozoa ( $\mathrm{n}=90 / 183 ; 49.2 \%$ ) than STH $(n=16 / 98 ; 8.7 \%)(p<0.01)$. Protozoa species were found in $39.1 \%(45 / 115)$ of PLHIV and in $66.2 \%$ (45/68) of HIV negative participants. Fourteen species were identified; the most frequent was Blastocystis sp $(31.7 \% ; \mathrm{n}=58)$, followed by E. coli $(16.4 \% ; \mathrm{n}=30)$ and T. trichiura $(5.5 \% ; \mathrm{n}=10)$. Among protozoa parasites species, five were pathogenic: Blastocystis sp $(49.2 \%$; $\mathrm{n}=58)$, G. Duodenalis $(1.6 \% ; \mathrm{n}=3)$, E. histolytica / dispar $(1.6 \% ; \mathrm{n}=3)$, I. belli $(1 \%, \mathrm{n}=0.5)$ and Cryptosporidium $s p(0.5 \%, \mathrm{n}=1)$.

Poly-infections were found. The most frequent associations found were Blastocystis sp and E. coli $(\mathrm{n}=5)$, Blastocystis sp and Chilomastix $(C$.) mesnili $(\mathrm{n}=3)$, Blastocystis sp and $G$. duodenalis $(\mathrm{n}=2)$ (figure 1$)$. 


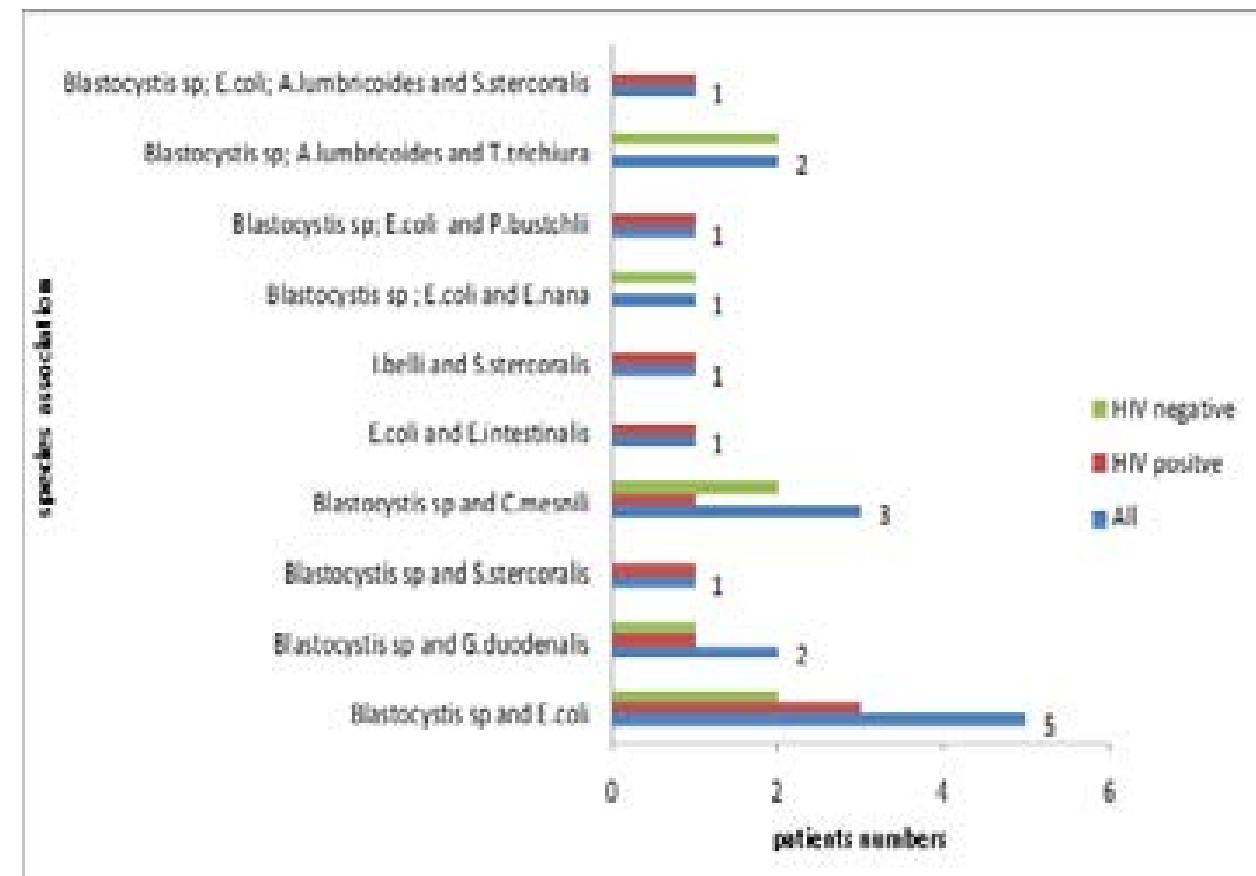

Figure 1: Parasites associations in the digestive tract

Table 2: Prevalence of parasite species among PLHIV and HIV negative participants

\begin{tabular}{|c|c|c|c|c|}
\hline & $\begin{array}{l}\text { All: N } \\
(\%)\end{array}$ & $\begin{array}{c}\text { PLHIV: } \\
\text { n(\%) }\end{array}$ & $\begin{array}{c}\text { HIV negative: } n \\
(\%)\end{array}$ & $\begin{array}{c}p \\
\text { value }\end{array}$ \\
\hline & $\begin{array}{c}\text { IP/Total } \\
(\%)\end{array}$ & IP/Total (\%) & IP/Total (\%) & \\
\hline Protozoa species & $\begin{array}{c}90 / 183 \\
(49.2)\end{array}$ & $\begin{array}{c}45 / 115 \\
(39.1)\end{array}$ & 45/68 (66.2) & \\
\hline Blastocystis sp & $58(31.7)$ & $26(22.6)$ & $32(47.1)$ & $0.006^{*}$ \\
\hline E. histolystica/dispar & $3(1.6)$ & $1(0.9)$ & $2(2.9)$ & 0.2 \\
\hline G. duodenalis & $3(1.6)$ & $2(1.7)$ & $1(1.5)$ & 0.8 \\
\hline E. coli & $30(16.4)$ & $15(13.0)$ & $15(22.1)$ & 0.1 \\
\hline E. nana & $6(3.3)$ & $1(0.9)$ & $5(7.4)$ & $<0.01^{*}$ \\
\hline P. butschlii & $1(0.5)$ & $1(0.9)$ & $0(0.0)$ & \\
\hline E. intestinalis & $1(0.5)$ & $1(0.9)$ & $0(0.0)$ & \\
\hline E.hartmani & $2(1.1)$ & $0(0.0)$ & $2(2.9)$ & \\
\hline C. mesnili & $7(3.8)$ & $5(4.3)$ & $2(2.9)$ & 0.6 \\
\hline Cryptosporidium sp & $1(0.5)$ & $1(0.9)$ & $0(0.0)$ & \\
\hline I. belli & $1(0.5)$ & $1(0.9)$ & $0(0.0)$ & \\
\hline Helminths & $16(8.7)$ & $8(6.9)$ & $8(11.8)$ & \\
\hline T. trichiura & $10(5.5)$ & $1(0.9)$ & $9(13.2)$ & $<0.01$ \\
\hline A. lumbricoides & $5(2.7)$ & $1(0.9)$ & $4(5.9)$ & 0.4 \\
\hline S. stercoralis & $8(4.4)$ & $7(6.1)$ & $1(1.5)$ & 0.1 \\
\hline \multicolumn{5}{|l|}{ Types of infection } \\
\hline Monoparasitism & $80(81.6)$ & $39(79.6)$ & $41(83.7)$ & \\
\hline Polyparasitism & $18(18.4)$ & $10(20.4)$ & $8(16.3)$ & 0.02 \\
\hline two & $13(13.3)$ & $8(16.3)$ & $5(10.2)$ & \\
\hline three & $4(4.1)$ & $1(2.0)$ & $3(6.1)$ & \\
\hline four & $1(1.0)$ & $1(2.0)$ & $0(0.0)$ & \\
\hline
\end{tabular}

$p$ value for comparison between HIV positive and HIV negative individuals 
Parasites infections distribution in the digestive tract according to HIV status

According to HIV status, the prevalence of intestinal parasites was significantly higher in seronegative participants: $72.1 \%(\mathrm{n}=49 / 68)$ vs $42.6 \%(\mathrm{n}=49 / 115)$ in PLHIV $(\mathrm{p}<0.01)$. I. belli and Cryptosporidium sp were only found in PLHIV (table 2). Three non-pathogenic species, E. hartmani, Embadomonas (E.) intestinalis, and $P$. butschlii, were only found in HIV infected patients. Blastocystis sp was more frequently detected in seronegative patients $47.1 \%$ versus $22.6 \%$ in PLHIV ( $\mathrm{p}=0.06$ ). The non-pathogenic species E. coli was found in $16.4 \%$ of participants; the frequency was not significantly different between the two groups $(22.1 \%$ vs $13.0 \%$ in PLHIV) ( $p=0.1)$. Compared to HIV-negative, PLHIV were more frequently poly-infected. Intestinal polyparasitism was found in ten PLHIV ( $\mathrm{n}=10 ; 20.4 \%)(\mathrm{p}=0.02)$ whose one had four parasites (table 2). The PLHIV co-infected by four different intestinal parasites species had A. lumbricoides; Blastocytis sp; E. coli and S. stercoralis (figure 1).

Intestinal parasites infection frequency in PLHIV and HIV negative individuals and associated factors

According to the age, IPI frequency decreased with age in PLHIV, ranging from $83 \%$ among the youngest to $36 \%$ among the oldest individuals; while more than two thirds of HIV negative individuals were infected in each group age $(<25 ; 25-55 ;>55$ years $)(p=0.09)$. Carriers of intestinal parasites were more common among women (>75\% in both groups) (tables 3 and 4). Almost all PLHIV $(97.5 \% ; n=39 / 49)$ and HIV negative participants $(75.0 \% ; n=33 / 49)$ infected by intestinal parasites drunk tap water; the remaining used river as source of drinking water. Likewise, almost $90 \%$ of PLHIV and HIV negative individuals with intestinal parasites used external toilets $(\mathrm{p}=0.1)$.

Table 3: Frequency of intestinal parasites among sero -positive and seronegative patients according to socio-demographic and behavioral factors

\begin{tabular}{|c|c|c|c|c|c|}
\hline \multirow[b]{2}{*}{ Gender } & \multicolumn{2}{|c|}{$\begin{array}{c}\text { HIV positive } \\
\text { with } \\
\text { parasite }(\mathrm{N}=49)\end{array}$} & \multicolumn{2}{|c|}{$\begin{array}{l}\text { HIV negative with } \\
\text { parasites }(\mathrm{N}=49)\end{array}$} & \multirow[t]{2}{*}{ Pvalue } \\
\hline & $\mathrm{n}$ & $\%$ & $\mathrm{n}$ & $\%$ & \\
\hline Females & 38 & 77.6 & 38 & 77.6 & 0.9 \\
\hline Males & 11 & 22.4 & 11 & 22.4 & \\
\hline Ages (years) & & & & & 0.009 \\
\hline$<25$ & 5 & 10.2 & 17 & 34.7 & \\
\hline $25-55$ & 32 & 65.3 & 20 & 40.8 & \\
\hline$>55$ & 12 & 24.5 & 12 & 24.5 & \\
\hline Education & & & & & 0.9 \\
\hline No school & 6 & 12.2 & 6 & 12.2 & \\
\hline School & 43 & 87.8 & 43 & 87.8 & \\
\hline $\begin{array}{l}\text { Drink water } \\
\text { type }\end{array}$ & & & & & 0.7 \\
\hline tap & 39 & 97.5 & 33 & 75.0 & \\
\hline river & 1 & 2.5 & 11 & 25.0 & \\
\hline $\begin{array}{l}\text { Household } \\
\text { water type }\end{array}$ & & & & & $<0.001$ \\
\hline tap & 25 & 64.1 & 37 & 75.5 & \\
\hline river & 5 & 12.8 & 7 & 14.3 & \\
\hline $\operatorname{mix}$ & 9 & 23.1 & 5 & 10.2 & \\
\hline Toilet & & & & & 0.1 \\
\hline inside & 5 & 12.8 & 5 & 10.2 & \\
\hline outside & 44 & 87.2 & 34 & 89.8 & \\
\hline
\end{tabular}


Table 4: factors associated with the presence of intestinal parasite in HIV individuals and all participants (Uni and Multivariate analysis)

\begin{tabular}{|c|c|c|c|c|c|c|c|c|c|}
\hline \multirow[b]{2}{*}{ Variables } & & \multicolumn{4}{|c|}{ All participants } & \multicolumn{4}{|c|}{ PLHIV } \\
\hline & & OR (95\% Cl) & Crude $p$ & aOR $(95 \% \mathrm{Cl})$ & Adj $p$ & OR $(95 \% \mathrm{Cl})$ & Crude $p$ & aOR (95\% Cl) & $\operatorname{Adj} P$ \\
\hline Gender & woman vs man & $1.52[0.78-2.95]$ & 0.21 & - & - & $2.01[0.639-6.35]$ & 0.23 & - & - \\
\hline \multirow[t]{2}{*}{ Age (years) } & {$[25-55]$ vs $<25$} & $0.33[0.13-0.84]$ & 0.02 & $0.24[0.08-0.69]$ & 0.00 & $0.14[0.01-1.30]$ & 0.80 & - & 0.08 \\
\hline & $>55$ vs $<25$ & $0.27[0.09-0.74]$ & 0.01 & $0.30[0.10-0.94]$ & 0.03 & $0.11[0.12-1.09]$ & 0.45 & - & 0.06 \\
\hline \multirow[t]{2}{*}{ Drink Water } & River vs tap & $0.72[0.30-1.73]$ & 0.47 & $0.50[0.19-1.30]$ & 0.15 & $0.13[0.01-1.10]$ & 0.06 & 0.12 [0.14-1.15] & 0.06 \\
\hline & Mix vs tap & $1.30[0.41-4.11]$ & 0.64 & $1.39[0.42-4.56]$ & 0.58 & $1.89[0.58-6.14]$ & 0.20 & $2.23[0.64-7.69]$ & 0.20 \\
\hline \multirow[t]{2}{*}{ Household water } & River vs tap & $0.58[0.24-1.40]$ & 0.22 & - & - & $0.55[0.16-1.89]$ & 0.88 & - & 0.34 \\
\hline & Mix vs tap & $0.80[0.33-1.94]$ & 0.62 & - & - & $0.90[0.31-2.59]$ & 0.03 & - & 0.84 \\
\hline Toilet & Yes vs no & $2.14[0.88-5.18]$ & 0.09 & $2.61[1.01-6.73]$ & 0.09 & $1.43[0.42-4.79$ & 0.56 & $1.8[0.47-6.82]$ & 0.5 \\
\hline CTX & Yes vs no & NA & NA & NA & NA & $1.53[0.69-39]$ & 0.28 & - & - \\
\hline ARVT & Yes vs no & NA & NA & NA & NA & - & - & - & - \\
\hline \multirow[t]{2}{*}{$\operatorname{CD} 4$ count $\left(/ \mathrm{mm}^{3}\right)$} & {$[200-500]$ vs $>500$} & NA & NA & NA & NA & $0.89[0.31-2.53]$ & 0.82 & - & - \\
\hline & $<200$ vs $>500$ & NA & NA & NA & NA & $0.34[0.52-6.33]$ & 0.34 & - & - \\
\hline
\end{tabular}

OR: odds Ratio; Cl: confidence interval; NA: not applicable; a: adjust. All the variables whose $p<0.2$ were adjusted.

Among PLHIV with complete data concerning ART and CTX intake, intake of CTX was not related to a significant decrease of IPIs frequency $(p=0.2)$ (table 3).The proportion of PLHIV infected was comparable between those who were on CTX and those who were not:32.2\% (19/59) vs38.6\%(17/44) $(\mathrm{p}=0.2)$.

The median CD4 count was $375245-640 / \mathrm{mm}^{3}$ and was known in 88 PLHIV. Nearly half of them $(46.6 \%$; $\mathrm{n}=41)$ had CD 4 counts between 200 and $500 / \mathrm{mm}^{3}$ and
$20.5 \%(\mathrm{n}=18)$ had CD4 counts below 200 cell $/ \mathrm{mm}^{3}$ (Table 1). Participants with CD4 count below 200 cell/ $\mathrm{mm}^{3}$ were more frequently infected by IPIs than those with higher CD4 count; although it was not statistically significant $(\mathrm{p}=0.9)$ (table 5). Depending on the CTX intake, the frequency of Blastocystis sp and G. duodenalis was similar in PLHIV S. Stercoralis and Blastocystis sp were common in PLHIV with CD4 lower $(\mathrm{p}=0.5)$. T. trichiura and Embadomonas intestinalis were only found among PLHIV with CD4 count below 200cell/ $\mathrm{mm}^{3}$.

Table 5: Frequency of intestinal parasites according to the use of cotrimoxazole prophylaxis, ART and the level of CD4 cell count

\begin{tabular}{lccccc}
\hline & $\begin{array}{c}\text { HIV with } \\
\text { parasites }\end{array}$ & $\%$ & $\begin{array}{c}\text { HIV without } \\
\text { parasites }\end{array}$ & $\%$ & p value \\
\hline Use of CTX & & & & & \\
Yes $(n=59)$ & 19 & 32.2 & 40 & 67.8 & $0.2^{*}$ \\
No $(n=44)$ & 17 & 38.6 & 27 & 61.4 & \\
& & & & & \\
ART & & & & & \\
No ( $n=3)$ & 0 & 0.0 & 3 & 100.0 & $0.2^{\alpha}$ \\
Yes ( $n=96)$ & 45 & 46.9 & 51 & 53.1 & \\
- First line(n=92) & 43 & 46.7 & 49 & 53.3 & \\
- Second line $(n=4)$ & 2 & 50.0 & 2 & 50.0 & \\
& & & & & \\
CD4 cell count $\left(/ \mathbf{m m}^{3}\right)$ & & & & & \\
$<200(n=18)$ & 10 & 55.6 & 8 & 44.4 & 0.4 \\
$200-500(n=41)$ & 18 & 43.9 & 23 & 56.1 & \\
$>500(n=29)$ & 12 & 41.4 & 17 & 58.6 & \\
\hline
\end{tabular}

${ }^{*} \mathrm{p}$ value for the comparison of IPIs frequency between participants on CTX and those were not. ${ }^{\alpha} \mathrm{p}$ value for the comparison of IPIs frequency between participants who took ART and those who did not. 


\section{Discussion}

Little is known about the epidemiology of intestinal parasites infections in people living with HIV in Gabon, especially in rural areas where intestinal infections are the most frequent ${ }^{15}$. Thus, this study shows that IPIs prevalence is high in this asymptomatic population of adults, although it was higher among the HIV seronegative ones. However, polyparasitism was highly detected among PLHIV. Protozoans were the most frequent parasites detected in both type of participants. The main species found was Blastocystis sp associated to E.coli. Presence of parasites was associated with the quality of the water used, the use of external toilet, but not with CTX and low CD4 count.

The study provides local data on IPIs prevalence and human reservoir among seronegatives individuals and PLHIV and on associated risk factors. These data are important for the design or the readjustment of control strategies for the prevention of these infections. Nevertheless, this study has some limitations. Stool samples were collected only once from the subjects, potentially accounting for the lower prevalence of intestinal helminths than of intestinal protozoa. The intensity of IPIs was not determined.

The overall prevalence of intestinal parasites infections found in the present study was $53.6 \%$ in the whole study population. This proportion was significantly higher among HIV uninfected patients compared to PLHIV (72.1\% vs $42.6 \%$ ) presumably due to antiretroviral treatment. In a study carried out in Ethiopia, HIV positive patients on ART had significantly lower prevalence of intestinal parasitic infection compared to HIV negative individuals. ${ }^{23}$

In this study, the majority of PLHIV was under ARTs. However, the impact of ART on IPIs is controversial. $^{24,25}$

Considering the parasites infection distribution, the prevalence found among HIV negative patients (72.1\%) is comparable to those obtained in previous studies performed in different areas of Gabon. ${ }^{14,15}$ In PLHIV, the frequency of IPIs $(42.6 \%)$ is higher than that reported in other African countries such as in Ethiopia (35.9\%) and Brazil $(28.8 \%) .^{26,27}$ Such difference may be explained by the study site location. These studies were conducted in both rural and urban areas, while the present study was exclusively carried out in rural areas. Indeed, in rural areas IPIs are more frequently encountered related to environmental conditions and inhabitants lifestyle.
Moreover, in the present study where the participants are all asymptomatic, the prevalence of IPIs in PLHIV is lower compared to that found in PLHIV with diarrhoea $(59.8 \%)$ by Assefa et al. ${ }^{10}$ In infected participants, protozoa were seven fold more frequent than helminths whatever HIV status. The same was true in other countries such as Malaysia (18.5\% vs $7.5 \%$ ) or in Ethiopia ( $76 \%$ vs $22.1 \%$ ) where intestinal protozoa were more frequently detected. ${ }^{4,10}$ This decrease of helminths frequency has also been observed in previous studies in Gabon. ${ }^{14,15}$ It may be due to self-medication by anthelminthic drugs in the populations in cases of diarrhoea or abdominal pain but also as a preventive measure. Despite the low prevalence of helminths, T. trichiura was found in $5.5 \%$ of individuals. It has been shown that this helminth was not fully sensitive to albendazole or mebendazole treatment. ${ }^{28}$ Nevertheless, the predominant species identified was Blastocystis sp in both populations as reported by others authors. ${ }^{7,10,14}$ This species was almost two-fold less frequent in PLHIV compared to HIV negative participants $(22.6 \%$ vs $47.1 \%)$. Such prevalence is similar to that found by Paboriboune et al $(26 \%)$ in Lao People's Democratic Republic. ${ }^{5}$ Blastocystis $s p$ usually considered as a commensal (non-pathogenic) protozoa living in the human intestine, is now described as a pathogen. ${ }^{29}$ It has been isolated in PLHIV having diarrhea. ${ }^{16,30}$ One study has shown that cotrimoxazole administered to PLHIV, with diarrhea and infected by Blastocystis sp, contributes to the recovery of these patients. ${ }^{31}$ In a study performed in Lambaréné, in the centre of Gabon, authors found a lower prevalence of intestinal helminths among patients taking cotrimoxazole compared to those who did not. ${ }^{32}$ In the present study the frequency of the infection did not vary according to the CTX intake presumably due to the sample size. This may hampered the clinical significance of CTX use in PLHIV use in the present study.

I. belli and Cryptosporidium sp $(<1.0 \%)$ were specifically found among people living with HIV confirming their opportunistic character. This low prevalence was similar to that found in PLHIV (3.8\%) in Brazil. ${ }^{27}$

Furthermore, the consumption of tap water and the use of external toilets were factors associated to the high prevalence of intestinal parasites (near 90\%) as reported elsewhere. ${ }^{33,34}$ Protozoa such as $G$. duodenalis and Cryptosporidium sp resist to the wastewater treatment process. ${ }^{35}$ Participants immunodepressed $\left(<200 \mathrm{cell} / \mathrm{mm}^{3}\right)$ had more frequently IPIs than PLHIV with higher level 
of CD4 count. This result was presumably not statistically significant due to the small sample size. In Nigeria, Ethiopia and other studies, the prevalence of IPIs was higher in subjects with low CD4 levels $(<200$ cell/ $\left.\mathrm{mm}^{3}\right) \cdot{ }^{36-40}$ Other authors reported a higher frequency of IPIs in PLHIV when CD4 rate was below 350cell/ $\mathrm{mm}^{3.31}$ Intestinal polyparasitism was found in $20.4 \%$ of PLHIV. Globally, the majority of them carried two parasites, four had three parasites and only one individual had four parasites. Most of the participants who had two or four parasites were people living with HIV (n $=10 ; 24.4 \%)$. In other studies polyparasitism occurred more commonly among HIV/AIDS individuals, and is frequently associated with low CD4+ T cell. ${ }^{39} \mathrm{~A}$ similar rate of infections was found in Algeria (15.4\%) but this was higher in Malaysia (71.4\%). ${ }^{40,41}$ This high rate could be due to the environmental conditions of rural areas, difficulty of access to drinking water and poor hygiene.

\section{Conclusion}

The overall prevalence of intestinal parasite infection is high with a predominance of protozoa in PLHIV living in rural areas in Gabon. Polyparasitism is not negligible in this population and infection with pathogenic intestinal parasites is also common even in the absence of clinical signs. Routine diagnosis of stools should be advocated for PLHIV better case management. As strategies are focused on HIV negative population, who carries the highest load of intestinal infections, sensitization on the preventive measures must be integrated for PLHIV. This study provides data that will contribute to a better management of PLHIV care

by identifying the parasites to which these participants were exposed.

\section{Conflict of interest}

The authors declare that they have no competing interest.

\section{Acknowledgements}

We are grateful to all the participants and the health workers who assisted with data collection. We acknowledge the HIV clinics staff for its collaboration with the Department of Parasitology-Mycology of the Faculty of Medicine.

\section{Contribution of authors}

K.L.J.V. collected sociodemographic, clinical and paraclinical data, performed lab diagnosis, statistical analysis, wrote, reviewed and approved the article.

P.N.B. collected sociodemographic, clinical and para- clinical data, performed lab diagnosis and approved the article.

M.N.P. and M.D.B collected sociodemographic, clinical and paraclinical data, performed lab diagnosis and approved the article.

N.N.J.M. collected sociodemographic, clinical and paraclinical data and approved the article.

M.D.A collected sociodemographic, clinical and paraclinical data and approved the article.

B.L.P. collected sociodemographic, clinical and paraclinical data and approved the article.

M.K.B.A. designed the study, wrote, reviewed and approved the article.

D.P.M.M. designed the study, wrote, reviewed and approved the article.

\section{References}

1. WHO. Sustaining the drive to overcome the global impact of neglected tropical diseases: second WHO report on neglected diseases: World Health Organization; 2013.https://www.who.int/neglected_diseases/9789241564540/en/. Consulted on 22nd january 2019.

2. ONUSIDA.2016.http://www.unaids.org/ sites/default/files/media_asset/UNAIDS_FactSheet_ fr.pdf.consulted on 25th may 2018.

3. Hailemeriam G, Kassu A, Abebe G, Abate E, Damte D, Mekonnen E, Ota F et al. Intestinal parasitic infection in HIV/AIDS and HIV seronegative individuals in Teaching Hospital, Ethiopia. J Inf Dis 2004; 57: 47-43.

4. Asma I, Johari S, Sim BLH and Lim YAL. How common is intestinal parasitism in HIV-infected patients in Malaysia? Tropical Biomedicine 2011 ; 28: 400410 .

5. Paboriboune P, Phoumindr N, Borel E, Sourinphoumy K, Phaxayaseng S, Luangkhot E et al. Intestinal Parasitic Infections in HIV-Infected Patients, Lao People's Democratic Republic. PLoS One 2014; 9(3): e91452

6. Noor R, RanjanSaha S, Rahman F, Munshi Kishore S, Aftab Uddin MD, Majibur Rahman. Frequency of opportunistic and other intestinal parasitic infections in patients infected with human immunodeficiency virus in Bangladesh. Tzu Chi Medical Journal 2012; 24: 191-195.

7. Tian LG, Chen JX, Wang TP, Cheng GJ, Steinmann P, Cai YC et al. Co-infection of HIV and intestinal parasites in rural area of China. Parasites \& Vectors 2012; 5:36.

8. Lehman LG, Kangam L, Nguepi E, Mbenoun 
ML, BilongBilong CF. Study of intestinal parasitic infections associated with HIV infection in Douala, Cameroon. Retrovirology 2012; 9:48.

9. Sarfati C, Bourgeois A, Menotti J, Liegeois F, Mouyou-Somo R, Delaporte E et al. Prevalence of intestinal parasites including microsporidia in human immunodeficiency virus-infected adults in Cameroon: A cross-sectional study. Am J Trop Med Hyg 2006; 74: 162-164

10. Assefa S, Erko B, Medhin G, Assefa Z and Shimelis. Intestinal parasitic infections in relation to HIV/AIDS status, diarrhea and CD4 T-cell count. Infectious Diseases 2009; 9:155.

11. Eshetu T, Sibhatu G, Megiso M, Abere A, Baynes HW, Biadgo B et al. Intestinal Parasitosis and Their Associated Factors among People Living with HIV at University of Gondar Hospital, Northwest Ethiopia. Ethiop J Health Sci 2017; 27:411-420.

12. Hosseinipour C, Napravnik S, Joaki G, Gama S, Mbeye N, Banda B, et al. HIV and Parasitic Infection and the Effect of Treatment among Adult Outpatients in Malawi Mina. The Journal of Infectious Diseases 2007; 195:1278-1282.

13. Walson JL, Stewart BT, Sangare L, Mbogo LW, Otieno PA, Piper BK et al. Prevalence and Correlates of Helminth Co-infection in Kenyan HIV-1 Infected Adults. PLoS Negl Trop Dis 2010; 4: e644.

14. M'bondoukwé NP, Mawili-Mboumba DP, Manga Mondouo F, Kombila M and Bouyou Akotet MK. Prevalence of Soil-transmitted Helminths and Intestinal Protozoa in Shanty Towns of Libreville, Gabon. International Journal of Tropical Disease \& Health 2016; 20: $1-9$.

15. M'bondoukwé NP, Kendjo E, Mawili-Mboumba DP, Koumba Lengongo JV, OffougaMbouronde C, Nkogue D et al. Prevalence of and risk factors for malaria, filariasis, and intestinal parasites as single infections or co-infections in different settlements of $\mathrm{Ga}$ bon, Central Africa. Infectious Diseases of Povrety 2018: $7: 38$

16. Adamu $\mathrm{H}$, Petros B. Intestinal protozoan infections among HIV positive persons with and without Antiretroviral Treatment (ART) in selected ART Centers in Adama, Afar and Dire-Dawa, Ethiopia. Ethiopian Journal of Health Development 2009; 23:133-140.

17. Framm SR \& Soave R. Agent of diarrhea. Medical Clinics of North America 1997; 81: 427-447.

18. Ministère de l'Économie, de l'Emploi et du Développement Durable. Ministère de la Santé Direction Générale de la Statistique, Libreville. Gabon En- quête Démographique et de Santé, 2012 ; UNFPA 245293.

19. Sapero JJ and Lawless DK. The MIF stain-preservation technique for the identification of intestinal protozoa. Am J trop Med Hyg 1953; 2:613-619.

20. Harada Y, Mori O. A New Method for culturing Hookworm. Acta Trop 1955; 1:177-359 PubMed .

21. Meurs L, PoldermanAM, Vinkeles Melchers NV et al. Diagnosing Polyparasitism in a High-Prevalence Setting in Beira, Mozambique: Detection of Intestinal Parasites in Fecal Samples by Microscopy and Real-Time PCR. PLoSNegl Trop Dis 2017; 23:e0005310.

22. Heinriksen SA and Pohlenz JF. Staining of cryptosporidia by Ziehl-Neelsen technique. Acta Vet Scand 1981: 22: 594-596.

23. Taye B, Desta K, Ejigu S, Urge Dori G. The magnitude and risk factors of intestinal parasitic infection in relation to Human Immunodeficiency Virus infection and immune status, at ALERT Hospital, Addis Ababa, Ethiopia. Parasitology International. 2014; 63:550556.

24. Udeh EO, Obiezue RNN, Okafor FC, Ikele CB, Okoye IC, Otuu CA. Gastrointestinal Parasitic Infections and Immunological Status of HIV/AIDS Coinfected Individuals in Nigeria. Ann Glob Health. 2019; $5: 85$

25. Abange WB, Nkenfou CN, Gonsu Kamga H, Nguedia CA, Kamgain N, Lozupone C et al.Intestinal Parasites Infections among HIV Infected Children Under Antiretrovirals Treatment in Yaounde, Cameroon. J Trop Pediatr. 2019.

26. Gedle D, Kumera G, Eshete T , Ketema K, Adugna $\mathrm{H}$ and Feyera $\mathrm{F}$. Intestinal parasitic infections and its association with under nutrition and CD4 $\mathrm{T}$ cell levels among HIV/AIDS patients on HAART in Butajira, Ethiopia. Journal of Health Population and Nutrition 2017; 36:15.

27. Barcelos NB, Silva L, Guimarães Dias RF, Filho HR, Rodrigues RM. Opportunistic and non-opportunistic intestinal parasites in HIV/ AIDS patients in relation to their clinical and epidemiological status in a specialized medical service in Goiás, Brazil. Rev Inst Med Trop São Paulo. 2018; 60:e13.

28. Levecke B, Montresor A, Albonico M, Ame SM, Behnke JM, Bethony JM et al. Assessment of anthelmintic efficacy of mebendazole in school children in six countries where soil-transmitted helminths are endemic. PLoS Negl Trop Dis. 2014; 8:10.

29. El-Shazly AM, Abdel-Magied, El-Beshbishi SN, El-Nahas HA, Fouad MA, Monib MS. Blastocystis 
hominis among symptomatic and asymptomatic individuals in Talkha Center, Dakahlia Governorate, Egypt. J Egypt. Soc. Parasitolol 2005; 35:653-666.

30. Jegede EF, Oyeyi ET, Bichi AH, Mbah HA, Torpey K. Prevalence of intestinal parasites among HIV/AIDS patients attendingnfectious Disease Hospital Kano, Nigeria. Pan Afr Med J. 2014; e.2014.

31. Idris NS, Dwipoerwantoro PG, Kurniawan A, Said M. Intestinal parasitic infection of immunocompromised children with diarrhoea: Clinical profile and therapeutic response. J Infect Dev Ctries. 2010; 4:309-317. 32. Janssen S, Hermans S, Knap M, Moekotte A, Rossatanga EG, Adegnika AA et al. Impact of Anti-Retroviral Treatment and Cotrimoxazole Prophylaxis on Helminth Infections in HIV-Infected Patients in Lambaréné, Gabon. PLoS Negl Trop Dis. 2015; 9: e0003769. 33. KibetKipyegen C, ShavulimoShivairo R, Ogwangodhiambo R. Prevalence of intestinal parasites among HIV patients in Baringo, Kenya. Pan African Medical Journal. 2012 ; 13:37.

34. BarkhoriMahni M, Rezaeian M, Kia EB, Raeisi A, Khanaliha K, Tarighi $F$ et al.,Prevalence of Intestinal Parasitic Infections in Jiroft, Kerman Province, Iran. Iran J Parasitol 2016; 11: 232-238.

35. Almeida A, Moreira MJ ,Soares S, Delgado Mde L, Figueiredo J, Silva E et al. Presence of Cryptosporidium spp. and Giardia duodenalis in Drinking Wa- ter Samples in the North of Portugal. Korean I Parasitol 2010; 48: 43-48.

36. Akinbo FO, Okaka CE and Omoregie R. Prevalence of intestinal parasitic infections among HIV patients in Benin City, Nigeria. Libyan J Med 2010; 5: 5506. 37. Fekadu S, Taye K, Teshome W, Asnake S. Prevalence of parasitic infection in HIV-positive patients in southern Ethiopia : A cross-sectional study. J infect Dev Ctries 2013; 7: 868-872.

38. Kiros H, Nibret E, Munshea A, Kerisew B, Adal M. Prevalence of intestinal protozoan infections among individuals living with HIV/AIDS at Felegehiwot Referral Hospital, Bahir Dar, Ethiopia. International Journal of Infectious Diseases 2015; 35: 80-86.

39. Akinbo F O, Omoregie R. Intestinal parasitic infection in human-immunodeficiency-virus-infected persons on highly active antiretroviral therapy in Benin City, Nigeria. Genomic Medicine, Biomakers, and Health Sciences 2011; 3:119-122.

40. Al-Delaimy AK, Al-Mekhlafi HM, Lim YAL, Nasr NA, Sady H, Atroosh WM et al. Epidemiology of intestinal polyparasitism among Orang Asli School Children in Rural Malaysia. PLoSNegl Trop Dis 2014; 8 : 307.

41. Benouis A, Bekkouche Z and Benmansour Z. Epidemiological study of human intestinal parasitosis in C.H.U. of Oran (Algeria). International Journal of Innovation and AppliedStudies 2013 ; 2 : 613-620. 